\title{
Degradation in Fatigue Crack Propagation Resistance of a Gas Turbine Vane after Long Term Service.
}

\author{
Masakazu OKAZAKI ${ }^{1,}$, , Motoki SAKAGUCHI ${ }^{1}$, Yosuke SASAKI ${ }^{1}$ \\ and Koichi NAMBA ${ }^{2}$ \\ ${ }^{1}$ Nagaoka University of Technology,Tomioka, Nagaoka, Japan. \\ ${ }^{2}$ Full Mitsui Engineering \& Shipbuilding CO., Tama 3-Chome, Tamano, Okayama, Japan \\ aokazaki@mech.nagaokaut.ac.jp
}

\begin{abstract}
Key words: Gas turbine vane after long term service, Ni-base superalloy, Leading and trailing edges, Miniature size specimen, Fatigue crack, Reheat treatment.
\end{abstract}

\begin{abstract}
Degree of long term degradation damage of a retired gas turbine vane made of a Ni-based superalloy which had been operating for about $20000 \mathrm{hrs}$ in a land-based gas turbine, was experimentally evaluated, through an assessment on the change in fatigue crack propagation resistance. For the purpose, a new testing apparatus has been developed to measure the local area fatigue crack propagation resistance, by extracting the miniature size compact tension specimens from the vane, where the specimens were extracted from the leading and the trailing edge, respectively. It was shown, the propagation rate of the crack that grew at the trailing edge part was significantly higher that that at the leading edge part. It was also shown that the crack propagation rates in the miniature specimen were generally higher than those in the standard size specimen. In order to explore an possibility to recover the degradation damage, the effect of a simple reheat treatment on the fatigue crack propagation resistance was also investigated.
\end{abstract}

\section{Introduction}

Hot section components in advanced industrial gas turbines, such as blades or vanes, have to operate under a severe combination of mechanical and environmental loadings. This service condition inevitably causes many types of damages and degradations in components during the operation period. Materials used in them, especially Ni-base superalloys, are so expensive items that they can be a substantial part of an operating and a maintenance budget [1-9]. Therefore, it is of considerable technical and financial benefit if the condition of the blades can be assessed and their remaining life determined. Whilst some efforts have been made to investigate the microstructural evolutions [2,3] or the degraded creep properties of post-service gas turbine superalloys [4], little is known about their fatigue properties, those may often depend on the location in the components. A difficulty in this problem has been mainly attributed to a technical hurdle in extracting standard size specimen from actual components which usually have thin wall structures, and also due to a lack of appropriate fatigue or crack propagation testing methods, employing small size specimens. The first objective in this study is to experimentally make clear the fatigue crack propagation resistance of the post-service gas turbine superalloy, using a miniature compact tension (CT) specimen extracted either from the leading or trailing edge part in the post-service actual gas turbine vane, and to compare with that of a conventional virgin material.

In recent gas turbines, on the other hands, some repair techniques have been tried to extend the lives of turbine blades and vanes. For instance, many types of diffusion brazing processes have been developed and utilized to the repairing of cracks [3,6]. Hot Isostatic Pressing (HIP) has also been used [7]. Even though these may successfully enhance the remaining lives of hot section components, they need considerable processing costs, resulting in the increase of the life cycle cost. Thus, inexpensive repair technologies have been required. It is the second objective of this work to investigate an usefulness of a simple reheat treatment [10] to recover the degradation of the aged superalloy components. 


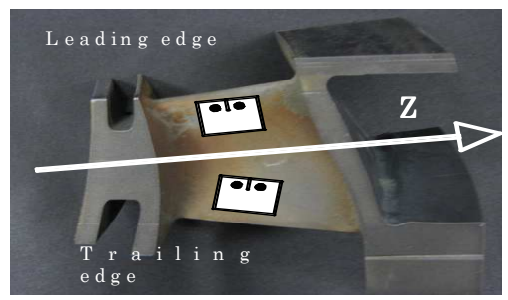

(a)

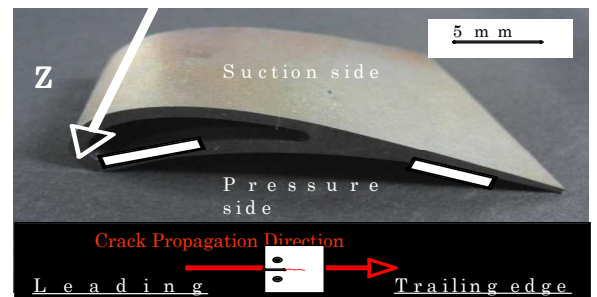

(b)

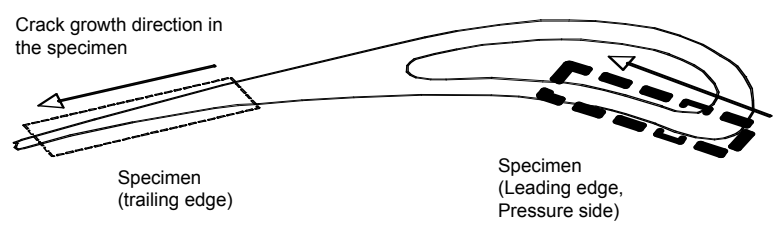

(c)

Fig.1 The post-service gas turbine vane and how to extract the specimens.

(a) Overview (b) Transverse cross section of the vane and the site for the specimens extracted

(c) How to extract the specimens

\section{Experimental Procedures}

\subsection{Materials}

The target in this work is a retired post-service gas turbine vane which had been fabricated by conventional casting and had worked for about 20000 hours as the $1^{\text {st }}$ stage vane in a $1100^{\circ} \mathrm{C}$-class land-base gas turbine made by Mitsui Engineering \& Shipbuilding Co., LTD. The overview and cross section of the vane are shown in Fig.1(a) and Fig.1(b), respectively. The vane is made of a conventional cast polycrystaline Ni-base superalloy, Inconel 939 (hereinafter denoted by IN939), where the aluminizing coating was applied on the overall surface by about $50 \mu \mathrm{m}$ in thickness. Unfortunately the as-manufactured vane was not available in this study; thus, a virgin conventional cast Ni-base superalloy, Inconel 738LC(hereinafter denoted by IN738), was also prepared as a reference material.

\subsection{Specimen preparation}

The miniature compact tension (CT) specimens were extracted from four regions in the retired vane: leading edge, trailing edge, middle suction side and middle pressure side, respectively. The specimen thickness was $0.5 \mathrm{~mm}$ in which the aluminized area was completely eliminated. The specimen geometry was designed so that it was almost proportional to that recommended in ASTM E647[11], except for the specimen thickness. Hereinafter, a series of these specimens will be expressed by their native areas; e.g., by "aged trailing specimen". The extraction method is given elsewhere in detail [10].

\subsection{Fatigue crack propagation tests}

Fatigue loading was applied to the miniature CT specimen through two loading pins at both room temperature and $850^{\circ} \mathrm{C}$ in air condition. During the tests, loading amplitude was kept constant under a loading frequency of $10 \mathrm{~Hz}$ with a loading ratio $R=0.4$ (defined by $K_{\min } / K_{\max }$, where $K_{\min }$ and $K_{\max }$ are minimum and maximum stress intensity factor during a cyclic loading, respectively). The specimens were heated by the high frequency induction heating system, which can provide a uniform temperature distribution in the specimen gauge section within $3^{\circ} \mathrm{C}$. 
Table 1 Volume fraction and size of $\gamma^{\prime}$ in the post-service IN939 vane and virgin IN738.

\begin{tabular}{c|c|c}
\hline & Volume fraction of $\gamma^{\prime}(\%)$ & Average size of $\gamma^{\prime}(\mu \mathrm{m})$ \\
\hline Leading edge (IN939) & 52 & 0.62 \\
\hline Pressure side (IN939) & 51 & 0.59 \\
\hline Trailing edge (IN939) & 52 & 0.70 \\
\hline Suction side (IN939) & 52 & 0.65 \\
\hline IN738 Virgin & 49 & $0.67 *$ \\
\hline \multicolumn{2}{c}{} & $*$ Size of primary $\gamma^{\prime}$
\end{tabular}

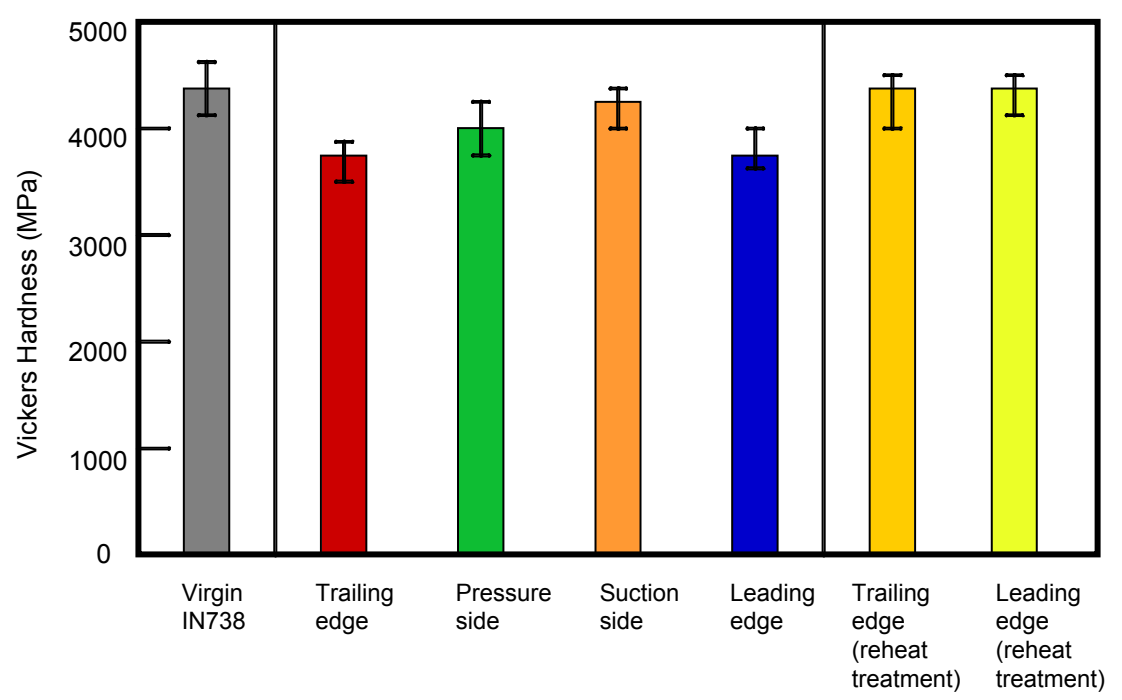

Fig. 2 Hardness distribution in the post-service vane.

\section{Results and Discussion}

\subsection{Metallography of the post-service gas turbine vane}

Table 1 summarizes the metallurgical analysis of the respective areas in the post service vane. It is worthy to note from Table 1 that the grain size in the trailing edge is significantly smaller than that in the other regions. This might be resulting from a difference in cooling rate during the cast process of the original vane. It is seen that the volume fraction of $\gamma^{\prime}$ precipitates; a major strengthening precipitates in Ni-base superalloys, was almost comparable between the respective areas. However, the size of $\gamma$ ' was relatively larger and more spheroidized in the trailing edge, compared with those in the other region. This suggests that the aging damage would be more significant at the trailing edge part than that at the other areas [10].

The hardness was measured at the midsection of the vane: Fig. 2. It is found that the hardness of the trailing and leading edge were lower, compared with that of the other areas. This suggest that the more pronounced damage might be evolved at the former two areas than the others. Meanwhile, the hardness of the virgin IN738 was higher than those of all regions in the IN939 post-service vane.

\subsection{Crack propagation resistance of post-service vane}

In Fig. 3 the fatigue crack propagation rates (FCPRs) in the post-service vane are correlated with the stress intensity factor range, $\triangle \mathrm{K}$, and compared with some results by other researchers $[8-10,12]$. The crack propagating at the trailing edge reveals the higher rate by a magnitude of a few times than that propagating at the leading edge part, especially in the high $\Delta K$ regime. In addition the rates at the former site are higher than those of the virgin IN738 specimen, whilst the rates at the latter site were almost comparable. Unfortunately the virgin IN 939 vane could not be prepared in this work, hence, it is difficult to explicitly confirm the reason for the higher FCPR at the trailing edge. 


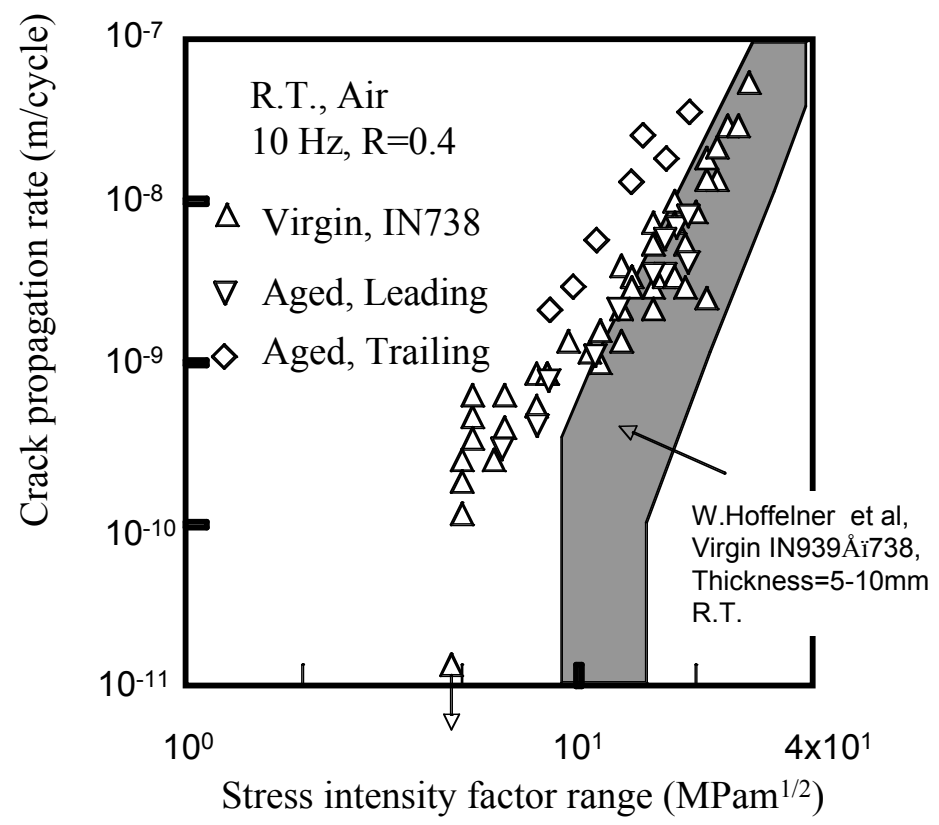

(a)

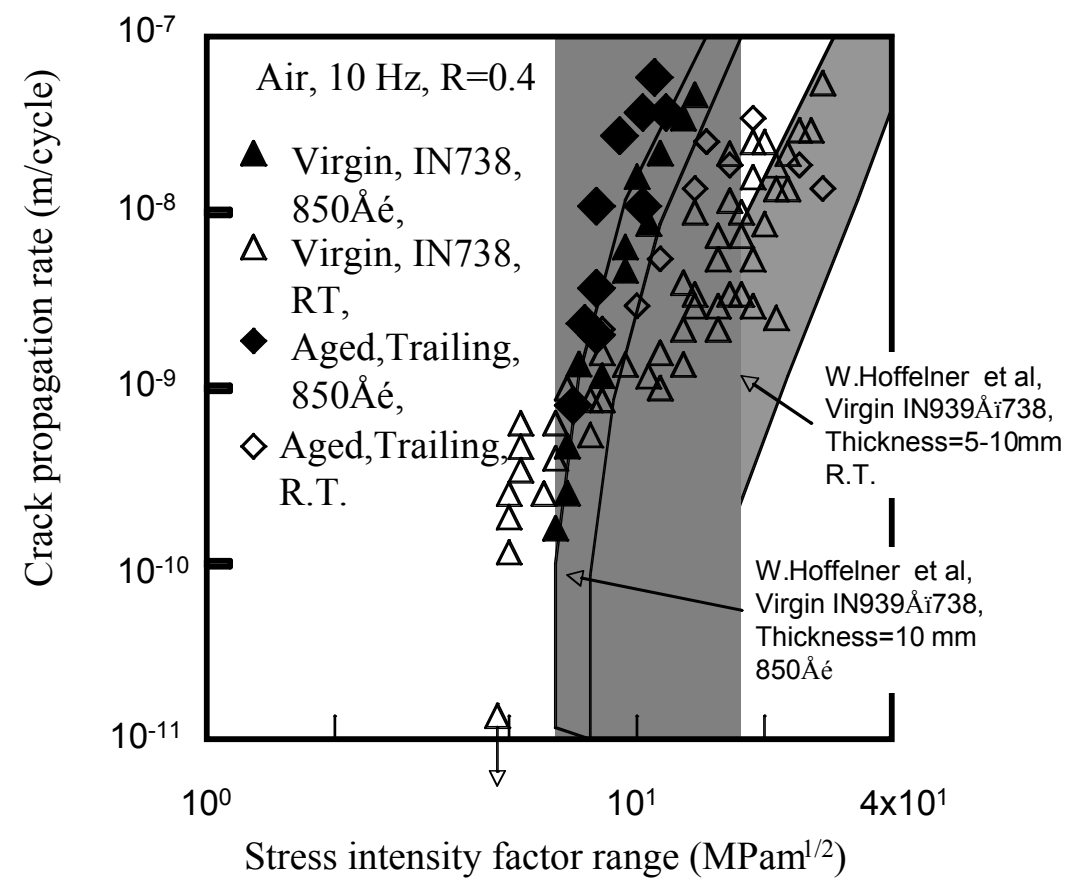

(b)

Fig. 3 The fatigue crack propagation rates those were significantly dependent on the crack propagating site in the post-service vane. (a) at room temperature, (b) at $850^{\circ} \mathrm{C}$.

However, from the following two reasons it is reasonable to postulate that the difference between the trailing and leading edge parts would be taken place during the service period, and not from the difference in grain size in the both areas. The first is from such an experimental results that the FCPRs at the former part were significantly changed after applying the reheat treatment, which will be shown later (Fig. 4). The other is from such findings that the FCPRs are generally insensitive to the yield strength of materials, rather more sensitive to elastic modulus [10-13]: in the other words, the FCGR of the virgin IN939 must be comparable to that of the virgin IN738, because of comparable elastic modulus between the both materials. This postulation is not in conflict to the hardness measurement shown in Fig. 2. 
Figure $3(\mathrm{~b})$ shows the FCGRs at $850^{\circ} \mathrm{C}$, indicating that the FCPRs at $850^{\circ} \mathrm{C}$ were higher than those
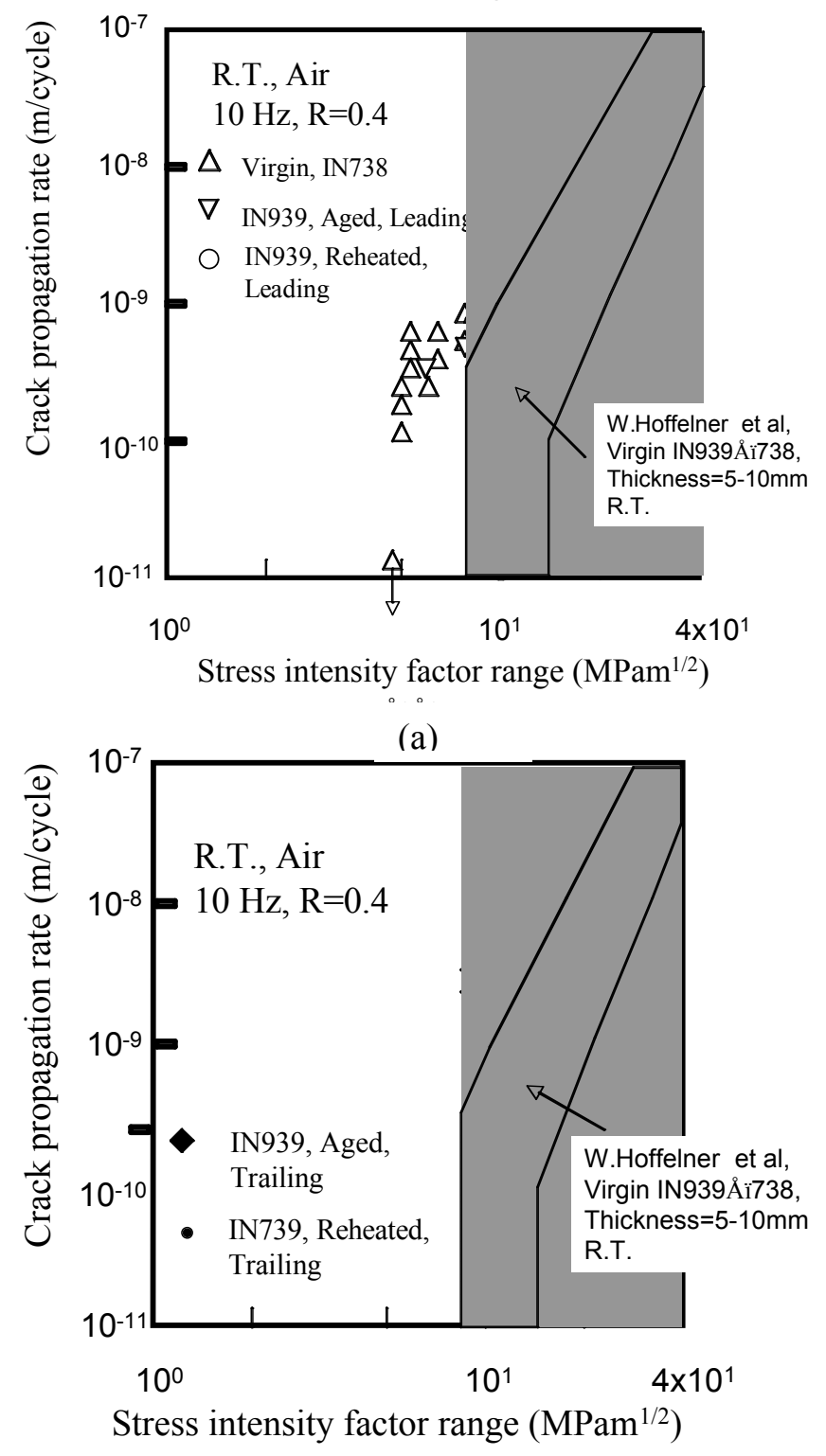

(b)

Fig.4 Effect of reheat treatment on FCPRs.

(a) Trailing edge part, (b) Leading edge part.

at room temperature. It is also found from Fig. 3(b) that the rates at the trailing edge part were still higher by about two times than those in the virgin IN738; an additional evidence suggesting a significant reduction of fatigue failure resistance there.

\subsection{Effect of reheat treatment on crack growth behavior}

The effect of a simple reheat treatment, $1120^{\circ} \mathrm{C} \times 2 \mathrm{~h}$, followed by an aging at $845^{\circ} \mathrm{C} \times 24 \mathrm{~h}$ in air, on the hardness is given in Fig. 2, which shows the treatment was effective to recover the reduced hardness for the present post service IN939. Figure 4 reveals the effect of a simple reheat treatment $\left(1120^{\circ} \mathrm{C} \times 2 \mathrm{~h}\right.$, followed by an aging at $845^{\circ} \mathrm{C} \times 24 \mathrm{~h}$ in air) for the present post service IN939 on the FCPRs. Of particular importance in Fig. 4 is that the FCGRs at the trailing edge part were decreased by a half magnitude by the treatment, while the effect was not so pronounced at the leading edge. It is not necessary to say that these results show an effectiveness of reheat treatment to recover the fatigue crack growth resistance of the post service gas turbine vane. At the same time the difference in the effect of heat treatment on FCPR between the trailing and leading edges indicates that the difference seen in Fig. 3 should be attributed to a reduction of resistance itself to fatigue failure during the service period. 


\section{Summary}

The conclusions derived in this work are summarized as follows:

(1) The testing method to evaluate the local area fatigue crack propagation resistance of the gas turbine vane was developed, by using the miniature CT specimens taken out from the thin wall gas turbine vanes. Here the thickness of the specimens was $0.5 \mathrm{~mm}$, and they were extracted from the leading and the trailing edge of the actual post service gas turbine vane, respectively.

(2) In the post service vane the FCGR at the trailing edge part was significantly higher than that at the leading edge part. In addition, while the latter was almost comparable to that of the virgin IN738 LC, the former was noticeably higher. Thus, there might occur a reduction in fatigue failure resistance at the former part during the long term service period.

(3) The FCGR at the trailing edge part could be decreased by applying a simple reheat treatment, indicating the effectiveness of reheat treatment to recover the degradation of the superalloy components after long term service.

\section{Acknowledgement}

Financial supports by the Grain-in-Aid for Scientific Research by JSPS (No. 21246022) is greatly acknowledged.

\section{References}

[1] R. E. Schafrik, and S. Walston: Superalloys 2008, edited by R.C. Reed et al., TMS, (2008), p. 3.

[2] T. Kimura, T. Suzuki, Y. Koizumi, T. Yokokawa, H. Harada: J. Japan Inst. Metals, Vol.71, (2007), p.1041 (in Japanese).

[3] Z. Mazur, A. Luna-Ramirez, J.A. Juarez-Islas, A. Campos-Amezcua: Engineering Failure Analysis, Vol. 12 (2005), p.474.

[4] V.P.Swaminathan, N.S. Cherubu, W.M. Robinson: Proceeding of ASME Intyernational Gasturbine and Aero Engine Congress, Stickholm, Paper 98-GT-510 (1998).

[5] C. Pascal, R.M. Marin-Ayra, J.C. Tedenac, and C. Merlet: Materials Science \& Engineering, Vol. A341 (2003), p.144.

[6] M. K Dinkle, P. Heinz, F. Pyczak, A. Volek, M. Ott, A, R. F. Affeldt: Superalloys 2008, edited by R.C.Reed et al., TMS, (2008), p. 211.

[7] J. Ishii: The Gas Turbine Soc. Japan, Vol. 29 (2001), p.18 (in-Japanese).

[8] W. Hoffelner:Metallurgical Transactions A, Vol. 13A (1982), p.1245.

[9] R.B. Scarlin: Materials Science and Engineering, Vol. 21 (1975), p.139.

[10] M. Okazaki, M. Sakaguchi, K. Namba: Journal of Solid Mechanics and Materials Engineering, vol. 4 (2010), p.131.

[11] Annual Book of ASTM Standards: E647-00, Vol. 03.01, ASTM (2003), p.615.

[12] M. Okazaki, M.Yamada, H., and S. Nohmi: Metall. \& Mat. Trans. , vol.26 (1996), p.1021. 